\title{
Evaluation of Drying and Storage Conditions on Nutritional and Sensory Properties of Dried Galega Kale (Brassica oleracea L. var. Acephala)
}

\author{
Ana C. Araújo, Sara M. Oliveira, Inês N. Ramos, Teresa R. S. Brandão, \\ Maria J. Monteiro, and Cristina L. M. Silva \\ Centro de Biotecnologia e Química Fina (CBQF), Escola Superior de Biotecnologia, Centro Regional do Porto da \\ Universidade Católica Portuguesa, Rua Arquiteto Lobão Vital, Apartado 2511, 4202-401 Porto, Portugal
}

Correspondence should be addressed to Cristina L. M. Silva; clsilva@porto.ucp.pt

Received 8 July 2016; Accepted 23 August 2016; Published 9 January 2017

Academic Editor: Jorge Barros-Velázquez

Copyright (C) 2017 Ana C. Araújo et al. This is an open access article distributed under the Creative Commons Attribution License, which permits unrestricted use, distribution, and reproduction in any medium, provided the original work is properly cited.

\begin{abstract}
This work evaluated the effect of the air-drying temperature and vacuum packaging on quality and nutritional compounds of dehydrated galega kale, previously steam blanched, during 5 months of storage. When compared with the vacuum packaged kale, the packaging without vacuum yielded improved nutritional features, in general. This approach combined with a drying temperature of $40^{\circ} \mathrm{C}$ resulted in retention percentages of $62,38,92$, and $48 \%$ for vitamin $\mathrm{C}$, total phenolic content, total antioxidant capacity, and chlorophylls, respectively. The acceptance of the dried product by the consumer was assessed through a focus group. The participants classified the product as a practical and convenient alternative to cook healthier dishes. The appearance of dried galega kale was described as being fragile and being with nice smell, natural colour, and flavour similar to the fresh product. In conclusion, the herein presented product was addressed as an innovation with multiple possible applications in several recipes.
\end{abstract}

\section{Introduction}

Galega kale (Brassica oleracea) is a headless leafy cabbage with long petioles and large midribbed leaves, containing high levels of vitamins, protein, calcium, and magnesium [1]. It is mostly consumed in soups, being an important ingredient in the Iberian Peninsula diet $[2,3]$.

The short shelf life, consequent of the high moisture content, can be increased by storing this vegetable at refrigerating temperatures. However, this strategy is able to assure quality standards only for a few days [4]. To overcome this limitation, drying processes have been often used as alternatives to increase the shelf life of this easily perishable food product.

Convective drying is one of foremost drying techniques employed by food industry to dry vegetables. However, it can lead to degradation of naturally heat-sensitive substances, such as vitamins, antioxidants, minerals, pigments, and other bioactive compounds, due to high temperatures/times exposure. Furthermore, drying processes can promote irreversible cellular rupture, which can result in losses of tissue integrity and reduce hydrophilic properties [5]. To prevent and/or to reduce these deteriorating modifications, the biological products are often submitted to pretreatments before the drying procedure. Additionally, the optimization of the process using the correct pretreatment and air-drying temperature can reduce some losses and prevent enzyme activity responsible for undesirable changes in nutrients, flavour, texture, and colour during storage [6].

The acceptance of a product by the consumer is a very important factor to determine its success and profitability in the national and international markets. There are several sensory methods to evaluate the targeted consumer's reaction and opinion on a product and thus determine its market acceptance. Focus group, also called discussion group, aims at collecting qualitative data and has three essential components: directed data collection, interaction in the group discussion as the data source, and the active role of the researcher in stimulating group discussion for the collection of data [7]. Focus group has been frequently used in science to allow provision of data of a group, in a fast way and at low 
cost. Moreover, due to its great flexibility, it can be employed to analyse a wide range of topics, within a variety of contexts and individuals, including those not trained and with low education levels [7].

This work evaluates the effects of different drying temperatures and vacuum packaging on quality parameters and nutritional compounds of dried galega kale during twenty weeks of storage. The quality studies were based on retention percentages of vitamin $\mathrm{C}$, total antioxidant activity, total phenolic compounds, and chlorophylls. Colour parameters and rehydration rates were also assessed. The product acceptability to the consumer was also studied, based on quality assessment by a Focus group of the dried product and also after rehydration of galega kale in a typical Portuguese soup.

\section{Material and Methods}

All reagents were of analytical grade quality, without further purification. The solutions were prepared using deionised water (specific conductance less than $0.1 \mu \mathrm{S} \mathrm{cm}^{-1}$ ) and MilliQ water (resistivity $>18 \mathrm{M} \Omega \mathrm{cm}$ ), when stated.

Vegetable material of galega kale was obtained from a local farmer (Porto, Portugal), and no pesticides or fertilizers were used on its production.

2.1. Pretreatment. The leaves of fresh samples were washed with tap water, dried with absorbent paper, rolled, and sliced to a width of about $5 \mathrm{~mm}$. The samples were dried in the same day of harvest and the fresh sample was stored at $4^{\circ} \mathrm{C}$ until the chemical analysis, up to a maximum of three days. Before convective drying, kale portions of $100 \mathrm{~g}$ were pretreated with steam at $101.325 \mathrm{~Pa}$ for $1 \mathrm{~min}$ [8]. The excess of liquid consequent of pretreatment was removed with absorbent paper, while cooling to room temperature took place.

2.2. Drying Experiments. Galega kale was dried using a pilot plant convective tray dryer (Armfield UOP8, Ringwood, England) with forced air and controlled velocity and temperature. A digital balance (Sartorius, Goettingen, Germany), attached to the drying equipment and connected to a computer (Hewlett-Packard Vectra, CA, USA), recorded the weight every $3 \mathrm{~min}$. A mass of $100 \mathrm{~g}$ was divided into three similar portions and spread on three top trays of the drier. Samples were dried until constant mass, using air-drying temperatures of 40,55 and $70 \pm 2^{\circ} \mathrm{C}$ and a constant air velocity of $1.20 \pm 0.09 \mathrm{~ms}^{-1}$. These parameters were measured with a squirrel data logger (Grant Instruments 1023, Cambridge, England) and a vane anemometer (Airflow LCA 6000, Buckinghamshire, England), respectively.

The moisture content (\% dry basis) of the dried samples was determined using an air oven (Ehret, Emmendingen, Germany) set at $104^{\circ} \mathrm{C}$ during 16-18 h [9], and it was calculated on a percent dry basis of the average of three replicates of each sample. The level of dry matter was $17.7 \pm 0.3$ for fresh sample and $24.8 \pm 0.01,21.3 \pm 0.01$, and $25.5 \pm 0.01 \%$ for the samples dried at 40,55 , and $70^{\circ} \mathrm{C}$, respectively.

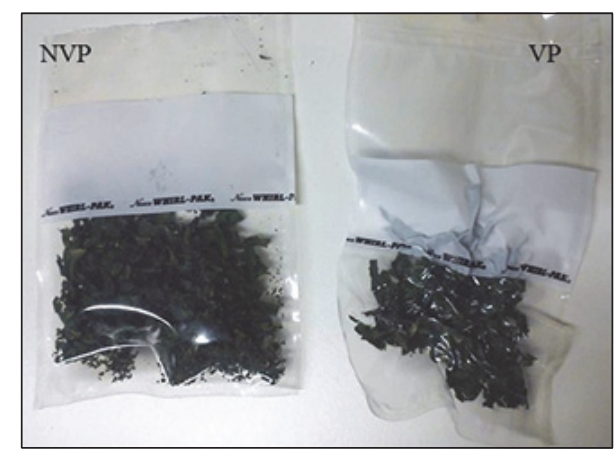

FIGURE 1: Dried galega kale packed without vacuum (NVP) and with vacuum (VP).

2.3. Packaging and Storage. After dehydration and cooling until room temperature, portions of $2 \mathrm{~g}$ of each dried sample were packaged in ten polyethylene bags (Whirl-Pak ${ }^{\mathrm{TM}}$ Sample Bags, Nasco ${ }^{\circledR}$, USA) with 2.5 mil of thickness. Another ten bags were subjected to vacuum packaging at 1 mbar during $1.2 \mathrm{~s}$ of welding, using a packaging machine (Multivac A300/41/42, Germany). The samples (Figure 1) were kept in a dark room, at room temperature, until a maximum period of five months. Analyses were performed every two weeks for each packaging approach.

2.4. Determination of Nutrients. Vitamin C was determined by HPLC analysis, as previously described [10]. Separation was carried in a reverse phase C18 silica analytical column (Waters Spherisorb ODS2 $5 \mu \mathrm{m} 4.6 \times 250 \mathrm{~mm}$ ). The extraction solution was prepared by dissolving $21.0 \mathrm{~g}$ of citric acid (Sigma Aldrich) and $0.05 \mathrm{~g}$ of EDTA (Merck) in $1.00 \mathrm{~L}$ of methanol $5 \%$ and degassed by ultrasound for $15 \mathrm{~min}$. Mobile phase and standard and OPDA solutions, as well as the colour reaction were prepared as described by Oliveira et al. [4]. The final coloured product was transferred into vials, which were placed on HPLC to be analysed. Four measurements were performed for each sample.

The samples extracts for analysis of total phenolic compounds, total antioxidant activity and chlorophylls, were prepared by homogenizing $10 \mathrm{~mL}$ of methanol $100 \%$ with $0.15 \mathrm{~g}$ of dried sample, with an ultraturrax (Ika digital T25, IKA $^{\circledR}$-Werke GmbH \& Co. KG, Staufen, Germany). The solutions were then centrifuged for $10 \mathrm{~min}$ at $5000 \mathrm{rpm}$ and $4^{\circ} \mathrm{C}$ and stored at the same temperature for 24 hours. The extracts were prepared in triplicate for each sample, and three measurements were performed for each extract. Total phenolic compounds, total antioxidant activity, and chlorophylls were determined spectrophotometrically, as previously described by Oliveira et al. [4].

2.5. Colour Properties. Colour parameters $L^{*}, a^{*}$, and $b^{*}$ of dried samples were determined with a Minolta CR-400 colorimeter (Konica-Minolta, Osaka, Japan). Three readings of three different replicates were made for each sample. Chroma, hue angle, total colour difference (TCD), and browning index (BI) were calculated from the values of $L^{*}, a^{*}$, and $b^{*}[11,12]$. 
TABLE 1: Estimates of model parameters (with confidence intervals at $95 \%, \mathrm{CI}_{95 \%}$, and coefficient of determination, $R^{2}$ ) of vitamin $\mathrm{C}$ degradation during 5 months of storage, for galega kale dried at different temperatures and packed with vacuum (VP) and without vacuum (NVP).

\begin{tabular}{|c|c|c|c|c|}
\hline \multirow{2}{*}{ Drying temperature $\left({ }^{\circ} \mathrm{C}\right)$} & \multirow{2}{*}{ Package } & \multicolumn{3}{|c|}{ Kinetic parameters } \\
\hline & & $C_{0}(\%) \pm \mathrm{CI}_{95 \%} / 2$ & $k\left(\%\right.$ week $\left.^{-1}\right) \pm \mathrm{CI}_{95 \%} / 2$ & $R^{2}$ \\
\hline \multirow{2}{*}{40} & NVP & $58.82 \pm 4.21$ & $1.75 \pm 0.37$ & 0.72 \\
\hline & VP & $54.51 \pm 4.73$ & $1.63 \pm 0.41$ & 0.66 \\
\hline \multirow{2}{*}{55} & NVP & $52.02 \pm 2.52$ & $1.47 \pm 0.22$ & 0.86 \\
\hline & VP & $46.55 \pm 3.39$ & $1.23 \pm 0.28$ & 0.73 \\
\hline \multirow{2}{*}{70} & NVP & $47.98 \pm 3.84$ & $1.68 \pm 0.35$ & 0.73 \\
\hline & VP & $47.49 \pm 3.42$ & $1.73 \pm 0.30$ & 0.82 \\
\hline
\end{tabular}

2.6. Rehydration. Six samples of dried matter with a mass of $2 \mathrm{~g}$ were placed in a container with $1 \mathrm{~L}$ of water at $80^{\circ} \mathrm{C}$. The temperature was maintained constant using a thermostatic bath. Samples were removed from the water after 1, 2, 4, 6, 8, and $10 \mathrm{~min}$ (in order to ensure that maximum rehydration capacity was evaluated), drained for $10 \mathrm{~min}$, and then weighed. The rehydration ratio (RR), expressed as $\mathrm{kg}$ of absorbed $\mathrm{H}_{2} \mathrm{O}$ per kg of dry matter, was calculated according to the following [13]:

$$
\mathrm{RR}=\frac{W_{\text {reh }} \cdot X_{\text {reh }}-W_{\text {dried }} \cdot X_{\text {dried }}}{W_{\text {dried }} \cdot\left(1-X_{\text {dried }}\right)}
$$

where $W_{\text {reh }}$ is the weight after rehydration, $X_{\text {reh }}$ is the water content on wet matter, $W_{\text {dried }}$ is the weight after drying process, and $X_{\text {dried }}$ is the corresponding moisture. Measurements were performed in triplicate and average values were calculated for each sample.

2.7. Sensory Analysis. As a compromise between the nutritional properties and the energetic cost of the dehydrated product, the sensory evaluation was performed on galega kale dried at $55^{\circ} \mathrm{C}$.

In order to evaluate the consumer's opinion about the product, a focus group [14] was gathered of nine participants with ages comprised between 23 and 50 years. Focus group took place in a special room prepared for sensory analysis, and the session was conducted by a moderator. After the meeting, the participants took product samples and prepared a soup at home, according to a provided recipe. In addition, a questionnaire was distributed to fill after proof of the soup made up by the participants.

2.8. Statistical Analysis. One-way ANOVA was performed to test the impact of drying treatments on quality indicators. Shapiro-Wilk and Levene tests were also used to test normality and data homoscedasticity. Alternative nonparametric tests, Kruskal-Wallis and posterior multiple comparisons based on Mann-Whitney tests, were used whenever the assumptions were not valid. All data analyses were performed using IBM SPSS Statistics.

2.9. Modelling Procedures. Whenever nutrients suffer decay throughout a storage period, kinetic models may describe such tendencies. In the case of vitamin C, a zero-order kinetic model was used in data fit $[15,16]$ :

$$
\frac{d C}{d t}=-k
$$

where $C$ is the amount of vitamin $C$ retained (\%) during the storage time $t$ and $k$ is the degradation rate.

The previous model allows obtaining a linear kinetic behaviour, considering that at time 0 the amount of vitamin $\mathrm{C}$ retained is $\mathrm{C}_{0}$ :

$$
C=C_{0}-k t
$$

This equation was fitted to experimental data and model parameters, $C_{0}$ and $k$, were estimated by linear regression analysis, using IBM SPSS Statistics. The model adequacy was validated by the normality, homoscedasticity, and randomness of the residuals (Kolmogorov-Smirnov test and visual inspection of the residuals) and by the coefficient of determination, $R^{2}$.

\section{Results and Discussion}

\subsection{Determination of Nutrients}

3.1.1. Vitamin C. Vitamin C is an indicator of the impact of processing on food quality, due to its high degree of water solubility and low stability during heat treatment [17].

The evolution of vitamin $\mathrm{C}$ degradation during five months of storage for both packages with and without vacuum is presented in Figure 2. The tendencies followed a zero-order kinetic model (3) and data fits are also included in the figure. Estimates of model parameters, that is, initial vitamin $C$ retention and degradation rate, are presented in Table 1 . In all situations the regressions were validated by the residual analyses, which proved normality, homoscedasticity, and randomness of the residuals and by the coefficient of determination. Models were adequate, and satisfactory high $R^{2}$ values were obtained.

Initial vitamin $\mathrm{C}$ retention was higher for $40^{\circ} \mathrm{C}$ and lower for $70^{\circ} \mathrm{C}$ in both packaging strategies. For NVP, retention percentages of $62.0 \pm 4.4,52.6 \pm 3.1$ and $48.5 \pm 1.6 \%$ were obtained after drying, using drying temperatures of 40,55 , and $70^{\circ} \mathrm{C}$, respectively. After 20 weeks of storage, the retention values were $30.3 \pm 2.6,28.4 \pm 1.1$, and $17.4 \pm 1.0 \%$ for the 

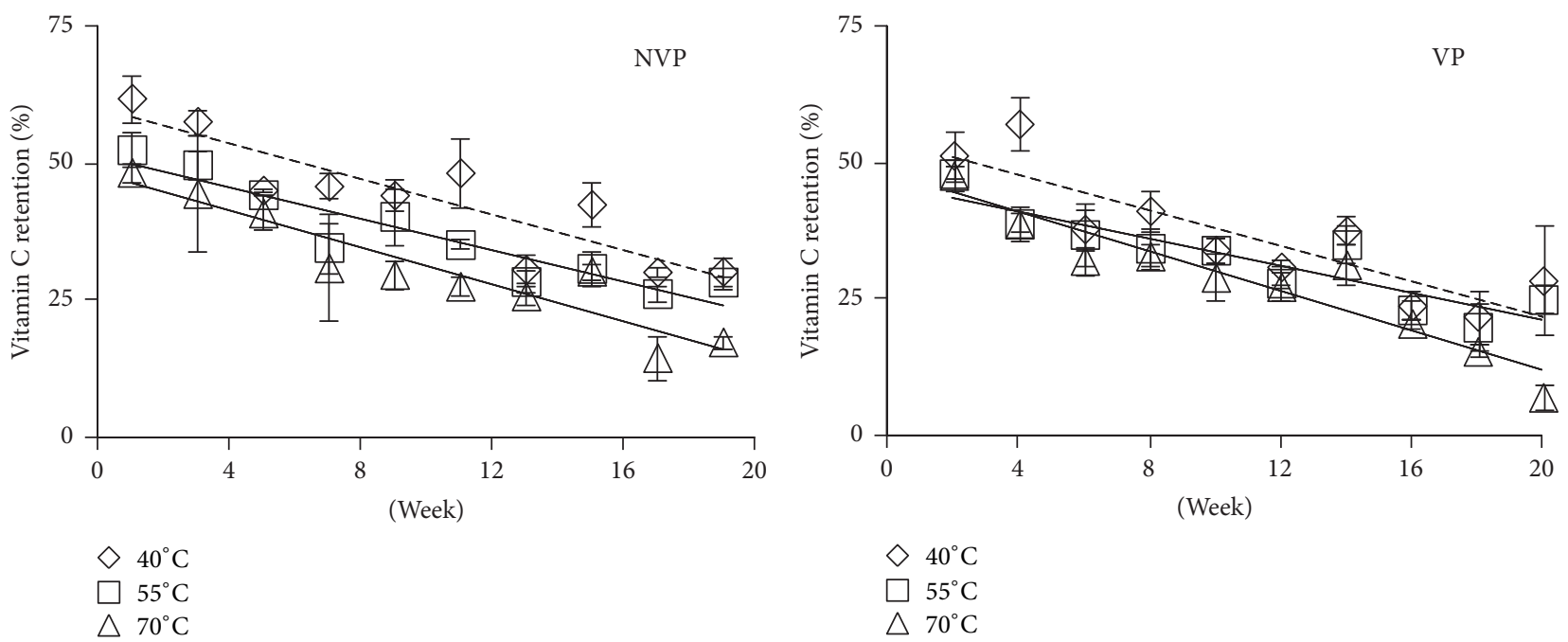

FIGURE 2: Vitamin C variation during twenty weeks of storage of galega kale dried at 40,55 , and $70^{\circ} \mathrm{C}$, packed without vacuum $(\mathrm{NVP})$ and with vacuum (VP). Bars are limits of standard deviation.

TABLE 2: Concentration of total phenolic content (TPC), total antioxidant capacity (TAOC), and total chlorophylls (TC), obtained for galega kale dried at 40,55 , and $70^{\circ} \mathrm{C}$, after 1 week (after drying) and 20 weeks of storage (after storage), using packaging with vacuum (VP) and without (NVP) vacuum.

\begin{tabular}{|c|c|c|c|c|c|}
\hline \multirow{2}{*}{ Nutrient } & \multirow{2}{*}{ Sample } & \multirow{2}{*}{ Packaging } & \multicolumn{3}{|c|}{ Drying temperature $\left({ }^{\circ} \mathrm{C}\right)$} \\
\hline & & & 40 & 55 & 70 \\
\hline \multirow{4}{*}{ TPC (mg GA/100 g d.m.) } & \multirow{2}{*}{ After drying } & NVP & $612.2 \pm 43.2^{\mathrm{a}}$ & $581.7 \pm 103.9^{\mathrm{a}}$ & $596.3 \pm 37.0^{\mathrm{a}}$ \\
\hline & & VP & $592.7 \pm 105.3^{\mathrm{a}}$ & $436.2 \pm 33.5^{\mathrm{b}}$ & $371.8 \pm 35.8^{\mathrm{b}}$ \\
\hline & \multirow{2}{*}{ After storage } & NVP & $351.1 \pm 59.0^{\mathrm{cd}}$ & $347.8 \pm 114.8^{\mathrm{cd}}$ & $307.3 \pm 42.4^{\mathrm{c}}$ \\
\hline & & VP & $438.8 \pm 38.2^{\mathrm{d}}$ & $366.2 \pm 40.1^{\mathrm{c}}$ & $321.8 \pm 55.1^{\mathrm{c}}$ \\
\hline \multirow{4}{*}{ TAOC (mg AA/100 g d.m.) } & \multirow{2}{*}{ After drying } & NVP & $1057.4 \pm 201.1^{\mathrm{a}}$ & $923.5 \pm 86.2^{\mathrm{a}}$ & $881.9 \pm 106.9^{\mathrm{a}}$ \\
\hline & & VP & $343.7 \pm 14.2^{\mathrm{b}}$ & $318.8 \pm 27.0^{\mathrm{b}}$ & $280.1 \pm 25.0^{\mathrm{b}}$ \\
\hline & \multirow{2}{*}{ After storage } & NVP & $333.1 \pm 44.9^{\mathrm{c}}$ & $288.7 \pm 21.9^{c}$ & $273.1 \pm 71.9^{\mathrm{cd}}$ \\
\hline & & VP & $221.9 \pm 15.3^{\mathrm{d}}$ & $123.1 \pm 71.9^{\mathrm{e}}$ & $105.3 \pm 48.8^{\mathrm{e}}$ \\
\hline \multirow{4}{*}{ TC (mg/100 g d.m.) } & \multirow{2}{*}{ After drying } & NVP & $459.8 \pm 68.4^{\mathrm{a}}$ & $429.1 \pm 67.5^{\mathrm{a}}$ & $424.1 \pm 103.4^{\mathrm{a}}$ \\
\hline & & VP & $565.9 \pm 76.0^{\mathrm{a}}$ & $432.8 \pm 26.4^{\mathrm{a}}$ & $364.6 \pm 76.5^{\mathrm{a}}$ \\
\hline & \multirow{2}{*}{ After storage } & NVP & $445.1 \pm 67.5^{\mathrm{b}}$ & $345.2 \pm 97.2^{\mathrm{b}}$ & $311.9 \pm 32.5^{\mathrm{b}}$ \\
\hline & & VP & $435.3 \pm 88.8^{\mathrm{b}}$ & $315.2 \pm 92.7^{\mathrm{b}}$ & $296.1 \pm 59.4^{\mathrm{b}}$ \\
\hline
\end{tabular}

Values of the fresh sample were TPC $=1609.8 \pm 42.3 \mathrm{mg} \mathrm{GA} / 100 \mathrm{~g}$ d.m., TAOC $=1145.5 \pm 201.1 \mathrm{mg} \mathrm{AA} / 100 \mathrm{~g}$ d.m., and TC $=952.0 \pm 88.8 \mathrm{mg} / 100 \mathrm{~g}$ d.m. Values with the same letter were not significantly different $(p>0.05)$.

samples dried at 40,55 , and $70^{\circ} \mathrm{C}$, respectively. Regarding the experiments with VP, the tested drying temperatures originated retention percentages of $51.5 \pm 4.4\left(40^{\circ} \mathrm{C}\right), 48.1 \pm 1.4$ $\left(55^{\circ} \mathrm{C}\right)$, and $47.8 \pm 3.1\left(70^{\circ} \mathrm{C}\right) \%$, after drying, and $28.4 \pm$ $9.9\left(40^{\circ} \mathrm{C}\right), 25.0 \pm 2.5\left(55^{\circ} \mathrm{C}\right)$, and $7.0 \pm 2.1\left(70^{\circ} \mathrm{C}\right) \%$ after 20 weeks of storage. These results indicate that higher airdrying temperatures resulted in more pronounced vitamin C degradation. Similar results were found for galega kale, collard leaves, and red pepper $[4,11,18]$. Moreover, the NVP presented higher vitamin $\mathrm{C}$ content after drying and also at the end of the storage period. Additionally, the retention percentages predicted by the kinetic model (Table 1) were 24,23 , and $14 \%$ for NVP versus 22,22 , and $13 \%$ obtained with VP, at 40,55 , and $70^{\circ} \mathrm{C}$, respectively. Rate constants were equivalent in all situations, indicating that degradation occurred at identical rates independently of the drying temperature applied and type of package used. The reduction of vitamin $\mathrm{C}$ during storage may be due to reaction of DAA with amino acids or proteins [19].

3.1.2. Total Phenolic Contents (TPC). Phenolic compounds and vitamin $\mathrm{C}$ represent $80 \%$ of the total antioxidant capacity of plant materials [17]. The concentration of TPC obtained for galega kale dried at 40,55 , and $70^{\circ} \mathrm{C}$, after 1 week (after drying) and 20 weeks of storage (after storage), using packaging with (VP) and without (NVP) vacuum, is presented in Table 2. According to the results, the major TPC losses were due to the drying process, although storage during 5 months also caused slight reductions in this parameter. In comparison to the fresh sample, which contained $1609.8 \pm 42.3 \mathrm{mg}$ of Gallic acid (GA) per $100 \mathrm{~g}$ of dry matter, retention values of approximately $37 \%$ were obtained for samples packaged 
TABLE 3: Values of $L^{*}, a^{*}$, and $b^{*}$ ( \pm standard deviation) obtained for galega kale dried at 40,55 , and $70^{\circ} \mathrm{C}$ after 1 week (after drying) and 20 weeks (after storage) of storage, using packages with vacuum (VP) and without (NVP) vacuum.

\begin{tabular}{lccccccc}
\hline \multirow{2}{*}{ Drying temperature $\left({ }^{\circ} \mathrm{C}\right)$} & \multirow{2}{*}{ Packaging } & \multicolumn{2}{c}{$L^{*}$} & \multicolumn{2}{c}{$a^{*}$} & $b^{*}$ \\
& & After drying & After storage & After drying & After storage & After drying & After storage \\
\hline \multirow{2}{*}{40} & NVP & $30.2 \pm 0.9^{\mathrm{a}}$ & $26.5 \pm 0.2^{\mathrm{c}}$ & $-5.6 \pm 0.7^{\mathrm{a}}$ & $-6.75 \pm 0.2^{\mathrm{c}}$ & $12.6 \pm 1.1^{\mathrm{a}}$ & $12.3 \pm 0.6^{\mathrm{d}}$ \\
& VP & $29.6 \pm 0.8^{\mathrm{a}}$ & $39.1 \pm 1.8^{\mathrm{d}}$ & $-9.3 \pm 0.9^{\mathrm{a}}$ & $-8.57 \pm 0.3^{\mathrm{d}}$ & $16.0 \pm 1.2^{\mathrm{b}}$ & $17.0 \pm 1.2^{\mathrm{e}}$ \\
\hline \multirow{2}{*}{55} & NVP & $32.6 \pm 1.5^{\mathrm{a}}$ & $30.0 \pm 0.1^{\mathrm{e}}$ & $-12.6 \pm 0.4^{\mathrm{b}}$ & $-7.84 \pm 0.2^{\mathrm{e}}$ & $16.1 \pm 0.7^{\mathrm{b}}$ & $14.2 \pm 0.5^{\mathrm{f}}$ \\
& VP & $30.6 \pm 0.8^{\mathrm{a}}$ & $28.0 \pm 1.1^{\mathrm{f}}$ & $-9.7 \pm 0.7^{\mathrm{a}}$ & $-7.24 \pm 0.2^{\mathrm{e}}$ & $15.2 \pm 1.2^{\mathrm{b}}$ & $13.3 \pm 0.5^{\mathrm{f}}$ \\
\hline \multirow{2}{*}{70} & NVP & $22.7 \pm 0.7^{\mathrm{b}}$ & $30.4 \pm 0.2^{\mathrm{e}}$ & $-8.5 \pm 0.4^{\mathrm{a}}$ & $-8.65 \pm 0.2^{\mathrm{d}}$ & $10.1 \pm 1.2^{\mathrm{c}}$ & $14.0 \pm 0.5^{\mathrm{f}}$ \\
& VP & $32.3 \pm 0.7^{\mathrm{a}}$ & $32.7 \pm 0.9^{\mathrm{g}}$ & $-9.7 \pm 0.5^{\mathrm{a}}$ & $-6.64 \pm 0.4^{\mathrm{c}}$ & $16.8 \pm 1.5^{\mathrm{b}}$ & $15.0 \pm 1.0^{\mathrm{f}}$ \\
\hline
\end{tabular}

Values of $L^{*}, a^{*}$, and $b^{*}$ with the same letter were not significantly different $(p>0.05)$.

Fresh sample: $L^{*}=35.2, a^{*}=-6.8$, and $b^{*}=7.3$.

without vacuum, regardless of the drying temperature. In the vacuum packaged samples, considering the fresh sample as reference, TPC retention values of 37,27 , and $23 \%$ were achieved, using drying temperatures of 40,55 , and $70^{\circ} \mathrm{C}$, respectively. These results indicate that TPC were negatively affected by the drying temperature when vacuum is applied to the packaging, probably due to modifications in the chemical structure of polyphenols that occur during drying, yielding the binding of polyphenols with other compounds, such as proteins [20]. TPC losses of 3-25\% were also reported in previous studies with galega kale, after 12 months of storage [6]. Hence, lower TPC losses were registered when an airdrying temperature of $40^{\circ} \mathrm{C}$ and vacuum packaging were employed.

3.1.3. Total Antioxidant Activity (TAOC). Naturally occurring antioxidants may also be target of deterioration as a consequence of processing and storage. The concentration of TAOC obtained for galega kale dried at 40,55 , and $70^{\circ} \mathrm{C}$, after 1 week (after drying) and 20 weeks of storage (after storage), using packaging with (VP) and without (NVP) vacuum, is presented in Table 2. The results indicate slight decreases of TAOC after drying when no vacuum packaging is employed during storage, with retention values of $77-92 \%$, considering the fresh sample as reference, which contained $1145.5 \pm$ $201.1 \mathrm{mg}$ of ascorbic acid (AA) per $100 \mathrm{~g}$ of dry matter. On the other hand, a pronounced decrease was observed in the vacuum packaged samples after drying (at the end of first week of storage) and also after 20 weeks of storage, which yielded TAOC retention percentages of 24-30 and 19-9\%, respectively. Therefore, the packaging strategy presented a crucial role on this quality parameter, and packaging under vacuum should be avoided to minimize TAOC degradation during storage. Moreover, using the latter approach, the storage presented a stronger influence on TAOC degradation than the convective drying, even when higher drying temperatures were used. However, for both packaging strategies, the TAOC retention decreased as the drying temperature increased, probably due to oxidation reaction promoted by heated air [21]. Thus, the best strategy to minimize TAOC deterioration consisted of combining a drying temperature of $40^{\circ} \mathrm{C}$ with packaging without the need of vacuum. This combination yielded negligible TAOC losses, with retention percentages above $90 \%$ after one week of storage and the highest retention after the 20 weeks of storage.

3.1.4. Total Chlorophylls (TC). Chlorophylls, responsible for the green colour of vegetables, are the most distributed natural pigments occurring in plants [22]. The convective drying, as well as twenty weeks of storage, resulted in significant chlorophylls losses, for both packaging strategies (Table 2). Table 2 presents the concentration of TC, obtained for galega kale dried at 40,55 , and $70^{\circ} \mathrm{C}$, after 1 (after drying) week and 20 weeks of storage (after storage), using packaging with (VP) and without (NVP) vacuum. In comparison with the fresh sample, which presented a content of $952.0 \pm 88.8 \mathrm{mg}$ of chlorophylls per $100 \mathrm{~g}$ of dry matter, the drying process originated total chlorophyll losses of $52-56$ and $38-60 \%$, for NVP and VP, respectively. After 20 weeks of storage, losses of 33-47 and 31-46\% were registered for NVP and VP, respectively. These results reveal that greater chlorophyll losses are due to the drying process, whereas storage and packaging strategy influences are practically insignificant, regarding chlorophyll content. These results may be explained by the sensitivity of these pigments to heat, oxygen, light, enzymes, $\mathrm{pH}$, and heavy metals, which can explain higher losses when exposed to high air-drying temperatures [22].

3.2. Colour Properties. The colour parameters $L^{*}, a^{*}$, and $b^{*}$ are indicated in Table 3 , and the results obtained for chroma, hue angle, TCD, and BI are presented in Figure 3. In general, the values of these parameters obtained for the samples dried at different temperatures and using both packaging approaches were very similar. The major differences were noticed at $70^{\circ} \mathrm{C}$, using NVP, which originated higher values of chroma, TCD, and BI. It was also evident that the main colour deterioration was observed at the beginning of storage and thus due to the drying procedure. These changes can be related to the development of the Maillard reaction, responsible for nonenzymatic browning [23, 24]. Moreover, storage of 5 months resulted in higher values of BI using NVP, probably because this reaction occurs frequently simultaneously with other reactions, which can be promoted by the presence of oxygen in the samples packaged with no vacuum. 

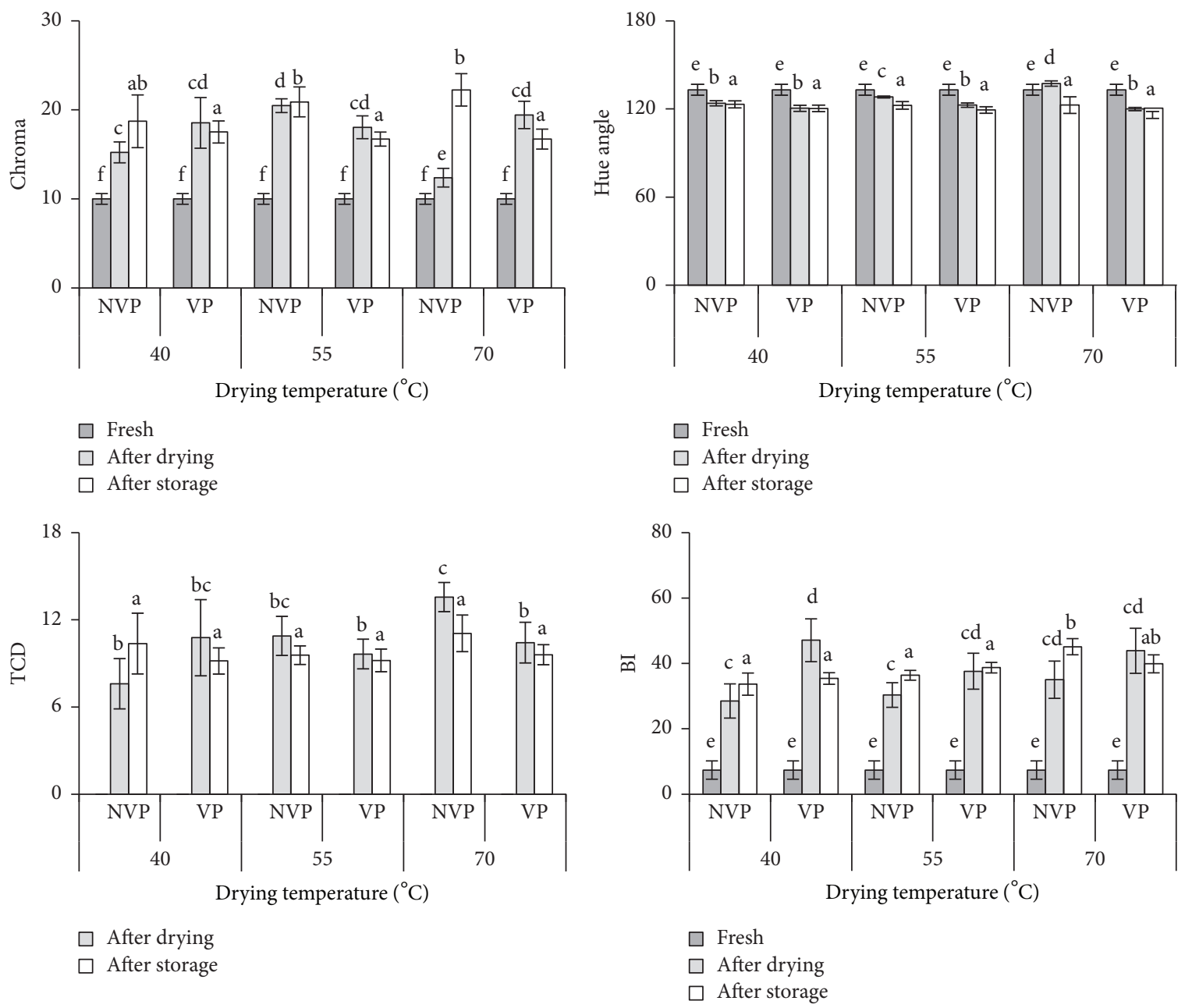

FIGURE 3: Average values of chroma, hue angle, total colour difference (TCD), and browning index (BI), obtained for galega kale that is fresh and dried at 40,55 , and $70^{\circ} \mathrm{C}$ packed with vacuum (VP) and without vacuum (NVP), after 1 week (after drying) and 20 weeks (after storage) of storage. Values with the same letter were not significantly different $(p>0.05)$. Bars are limits of standard deviation.

3.3. Rehydration. The RR was calculated (1) in order to understand the influence of air-drying temperature on the rehydration capacity of dried galega kale. As it can be observed from Table 4, the increase of the rehydration ratio was promoted by increasing air-drying temperatures, probably due to more pronounced tissue collapse and cell damage, which facilitated the water retention in the spaces previously occupied by them [13]. Hence, the rising values of rehydration ratios as the air-drying temperature increased reflected the negative impact of heat on sample. Therefore, the use of high drying temperatures may result in modifications in terms of structure and quality determinant for the consumer acceptability of the dehydrated product.

3.4. Sensory Analysis. To finalize the overall quality evaluation and assess the acceptability by the consumer, sensory analysis was performed using a Focus group [14]. The kale, previously steam blanched and dried at $55^{\circ} \mathrm{C}$, was incorporated/rehydrated in a well-known traditional soup (Figure 4), which was given to participants for evaluation.
TABLE 4: Values of rehydration ratio (RR) obtained after drying (before storage) of galega kale at different temperatures.

\begin{tabular}{lc}
\hline $\begin{array}{l}\text { Drying temperature } \\
\left({ }^{\circ} \mathrm{C}\right)\end{array}$ & $\begin{array}{c}\text { Rehydration rate } \\
\left(\text { kg absorbed } \mathrm{H}_{2} \mathrm{O} / \mathrm{kg} \text { dry matter }\right)\end{array}$ \\
\hline 40 & $2.81 \pm 0.03^{\mathrm{a}}$ \\
55 & $3.36 \pm 0.02^{\mathrm{b}}$ \\
70 & $3.66 \pm 0.02^{\mathrm{c}}$ \\
\hline
\end{tabular}

Values with the same letter were not significantly different $(p>0.05)$.

During the Focus group session, some questions were made to the participants concerning their opinions, perceptions, beliefs, and attitudes related to the product. The interaction and discussion were promoted between the participants, who usually buy and cook food. At the beginning of the session, none of the participants knew the product (dried galega kale) or any similar products and referred only to dried fruits, among dried products available in the market. 


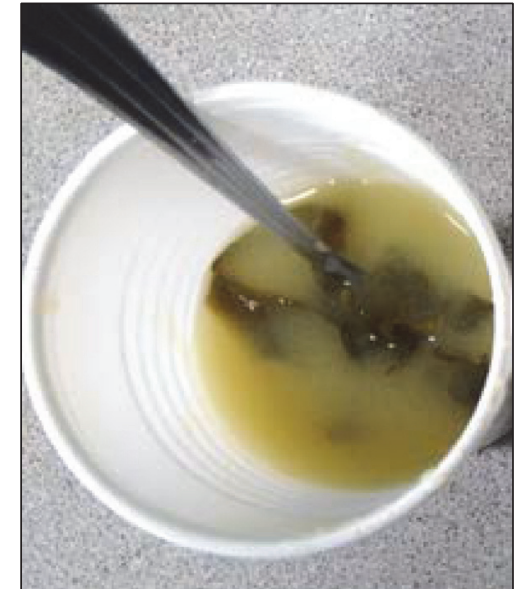

FIGURE 4: Sample rehydrated/incorporated in the soup distributed to the participants during the focus group session.

Participants described the product as being practical, being highly convenient, and presenting nice smell and a fragile appearance. An attractive colour, analogous to the natural product, was also addressed as a favourable point, since it gave the idea of being a nonintensively processed food. The product was considered as a good environmental idea, enabling waste reduction promoted by the enlarged shelf life. Before tasting the soup prepared for the session, the majority of the participants said that they would buy the product, except for two of them, who were not willing to. It was also noted that the product was ideal for special occasions, indecision situations (what can I do for dinner?), limited time to cook, or even regular use in soups by people who live in places where the access to fresh vegetables is limited or restricted.

The place where the product can be purchased from also constitutes an important aspect. The group suggested that the product should be sold in local supermarkets. In an early stage, the best strategy to disclose the product should be in a promotion stand, where the customer could be aware of all the making, visual appearance, and taste of the prepared product. Then, the product should be placed in a section near to fruits and vegetables. Another idea to explore could be the incorporation of the packaged dried kale into boxes for exportation, along with some Portuguese typical products.

In relation to the price, participants considered that a package containing $40 \mathrm{~g}$, a sufficient amount to prepare soup for four people, should present a cost of $2 €$ (2.19 USD).

Concerning the package, this should be provided with detailed information on the nutritional composition, emphasizing the absence of chemicals use to improve nutritional characteristics and final appearance. The print of a recipe on the package was also suggested, as a suggestion of use to ensure a successful first use of the product, in order to captivate customers and keep them faithful to the product. At the end of the discussion, participants tasted the prepared soup and a few more questions were addressed. The participants did not notice differences in the final appearance of

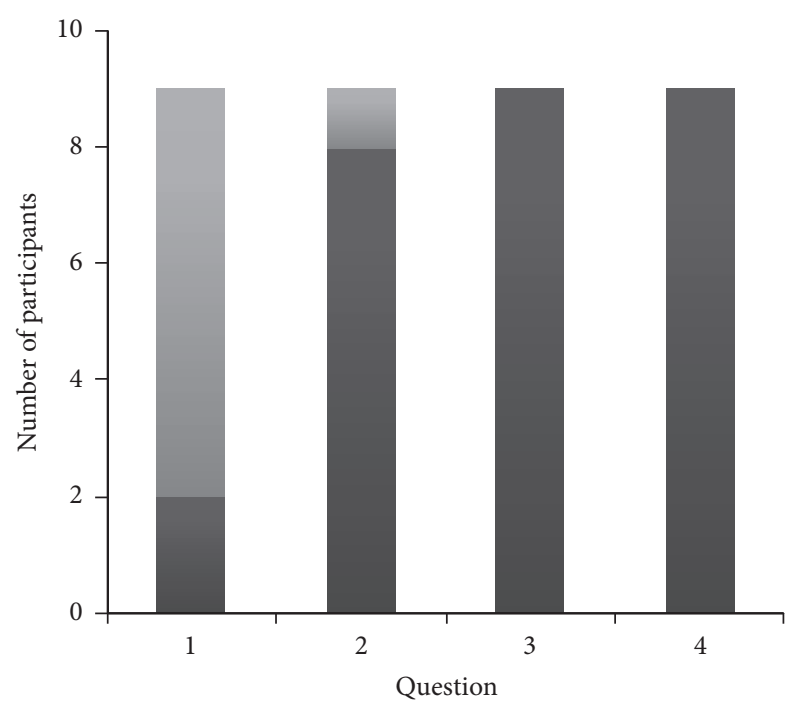

(1) Is the preparation method very different $\quad$ Yes using dried or fresh kale?

(2) Is the final appearance the expected?

(3) Regarding taste, is the product appropriate for this use suggestion?

(4) Besides incorporation into soups, will the product have another utility?

FIgURE 5: Results of the four questions presented in the questionnaire filled after soup preparation at home, using galega kale steam blanched and dehydrated at $55^{\circ} \mathrm{C}$.

soup and the one usually prepared at home with fresh galega kale. The thickness of kale was a bit larger than usual but was not addressed as a negative factor. The most positive aspects were the unchanged colour and the texture of the kale, which was described as softer than the fresh one. At this stage, participants were questioned again about the possibility of buying the product and all of them were willing to buy and pay a bit more than the fresh product. Moreover, the product was denoted as an authentic surprise and a real innovation for the national and international markets.

At the end of the focus group, packages containing $40 \mathrm{~g}$ of sample and a recipe of the soup were distributed to each participant, along with a questionnaire to answer after preparing the soup at home. The results of each question made in the questionnaire are presented in Figure 5. First question asked about differences in the methodology of soup preparation, using the dried or fresh kale. Two elements reported differences in the soup elaboration, due to the preliminary preparation of the kale, pointing out that the new proposed product enabled considerably easier and faster methodology. Final appearance was the second analysed aspect, and in this regard, the participants considered that the soup prepared by them corresponded to their expectations. Only one participant noted that the amount of sample provided was excessive for the quantity of soup prepared. In question three, about the flavour, all participants praised this parameter and considered the sample suitable for this suggestion of use. In the last question, related to other possible applications of the dried product, all participants 
Journal of Food Quality

of the group agreed that the product could have other utilities, such as incorporation in rice, risotto, pasta, and dishes that require coloured and/or healthy ingredients. In addition, the use of the product as a snack in countries where the concept was more common was suggested, such as USA.

\section{Conclusions}

The effect of vacuum packaging on nutritional compounds and quality parameters of dried galega kale, using three airdrying temperatures, was analysed during twenty weeks of storage. The higher drying temperature $\left(70^{\circ} \mathrm{C}\right)$ resulted in lower concentrations of all nutritional parameters, whereas the lowest tested temperature $\left(40^{\circ} \mathrm{C}\right)$ yielded higher values. Packaging using vacuum did not add value to the dried product, since similar or better results were obtained for most nutritional parameters using the samples packaged at normal atmosphere. All nutritional compounds decreased during the storage period, with vitamin $\mathrm{C}$ being the most affected. In relation to the colour properties, similar results were obtained for both packages at all drying temperatures, allowing concluding that packaging without the need of vacuum provided the attainment of a dried product with a visual aspect analogous to the sample packaged using vacuum.

As previously demonstrated by Oliveira et al. [4], the use of the lowest air-drying temperature resulted in lower nutrient losses, but when the drying temperature was changed from 40 to $55^{\circ} \mathrm{C}$, the drying period was significantly reduced from 360 to 200 minutes. Hence, the latter temperature was selected for sensory analysis experiments, as a compromise between the nutritional quality and the production cost of the dehydrated product.

Focus group was helpful to understand the consumer attitude towards the product and to give an idea concerning other utilities beyond the incorporations in soups, as well as the implementation of dehydrated kale in the market. The product was well accepted and considered a practical and tasty solution to prepare soups in a revolutionary way, fitting in the modern food concept.

\section{Additional Points}

Practical Applications. During the present work, the quality of a healthier food consisting of a dried vegetable was assessed. Several processes were evaluated, including the pretreatment applied before the drying process, the drying temperature, and the packaging strategy. The selected conditions were chosen aiming at minimizing nutrients losses and quality deterioration and also providing an alternative green vegetable with longer shelf life in comparison to the fresh product. The sensorial analysis was performed after rehydration of the dried product in a soup. However, the product could also be rehydrated and incorporated in different foods, such as pasta, rice, risotto, pizza, vegetarian recipes, and other dishes that employ coloured and/or healthy ingredients. Moreover, the product could also be consumed in the dried form, as a snack.

\section{Competing Interests}

The authors declare no competing interests regarding the publication of this paper.

\section{Acknowledgments}

S. M. Oliveira, I. N. Ramos, and T. R. S. Brandão gratefully acknowledge Fundação para a Ciência e a Tecnologia (FCT) and Fundo Social Europeu (FSE) for the financial support through the postdoctoral Grants SFRH/BPD/74815/2010, SFRH/BPD/75430/2010, and SFRH/BPD/101179/2014, respectively. This work was supported by National Funds from Fundação para a Ciência e a Tecnologia (FCT) through Project UID/Multi/50016/2013.

\section{References}

[1] G. Mwithiga and J. O. Olwal, "The drying kinetics of kale (Brassica oleracea) in a convective hot air dryer," Journal of Food Engineering, vol. 71, no. 4, pp. 373-378, 2005.

[2] S. C. Fonseca, F. A. R. Oliveira, J. M. Frias, J. K. Brecht, and K. V. Chau, "Modelling respiration rate of shredded Galega kale for development of modified atmosphere packaging," Journal of Food Engineering, vol. 54, no. 4, pp. 299-307, 2002.

[3] S. Martínez, I. Olmos, J. Carballo, and I. Franco, "Quality parameters of Brassica spp. Grown in northwest Spain," International Journal of Food Science and Technology, vol. 45, no. 4, pp. 776-783, 2010.

[4] S. M. Oliveira, I. N. Ramos, T. R. S. Brandão, and C. L. M. Silva, "Effect of air-drying temperature on the quality and bioactive characteristics of dried galega kale (Brassica oleraceaL. var. Acephala)," Journal of Food Processing and Preservation, vol. 39, no. 6, pp. 2485-2496, 2015.

[5] K. S. Jayaraman, D. K. Das Gupta, and N. Babu Rao, "Effect of pretreatment with salt and sucrose on the quality and stability of dehydrated cauliflower," International Journal of Food Science \& Technology, vol. 25, no. 1, pp. 47-60, 1990.

[6] A. Korus, "Effect of preliminary processing, method of drying and storage temperature on the level of antioxidants in kale (Brassica oleracea L. var. acephala) leaves," LWT-Food Science and Technology, vol. 44, no. 8, pp. 1711-1716, 2011.

[7] I. S. Silva, A. L. Veloso, and J. B. Keating, "Focus group: considerações teóricas e metodológicas," Revista Lusófona de Educação, vol. 26, pp. 175-190, 2014.

[8] A. C. Araújo, S. M. Oliveira, I. N. Ramos, T. R. S. Brandão, and C. L. M. Silva, "Influence of pretreatments on quality parameters and nutritional compounds of dried Galega kale (Brassica oleracea L. var. acephala)," Food and Bioprocess Technology, vol. 9, no. 5, pp. 872-881, 2016.

[9] AOAC, Association of the Official Analytical Chemists-Official Methods of Analysis, 2002.

[10] S. Zapata and J. Dufour, "Ascorbic, dehydroascorbic and isoascorbic acid simultaneous determinations by reverse phase ion interaction HPLC," Journal of Food Science, vol. 57, no. 2, pp. 506-511, 1992.

[11] I. Alibas, "Microwave, vacuum, and air drying characteristics of collard leaves," Drying Technology, vol. 27, no. 11, pp. 1266-1273, 2009.

[12] R. Ihns, L. M. Diamante, G. P. Savage, and L. Vanhanen, "Effect of temperature on the drying characteristics, colour, 
antioxidant and beta-carotene contents of two apricot varieties," International Journal of Food Science and Technology, vol. 46, no. 2, pp. 275-283, 2011.

[13] A. Vega-Gálvez, R. Lemus-Mondaca, C. Bilbao-Sáinz, P. Fito, and A. Andrés, "Effect of air drying temperature on the quality of rehydrated dried red bell pepper (var. Lamuyo)," Journal of Food Engineering, vol. 85, no. 1, pp. 42-50, 2008.

[14] H. Finch and J. Lewis, "Focus groups," in Qualitative Research Practice, J. Ritchie and J. Lewis, Eds., Sage, London, UK, 2003.

[15] E. M. Gonçalves, J. Pinheiro, C. Alegria, M. Abreu, T. R. S. Brandão, and C. L. M. Silva, "Degradation kinetics of peroxidase enzyme, phenolic content, and physical and sensorial characteristics in broccoli (Brassica oleracea L. ssp. Italica) during blanching," Journal of Agricultural and Food Chemistry, vol. 57, no. 12, pp. 5370-5375, 2009.

[16] E. M. Gonalves, M. Abreu, T. R. S. Brandão, and C. L. M. Silva, "Degradation kinetics of colour, vitamin $\mathrm{C}$ and drip loss in frozen broccoli (Brassica oleracea L. ssp. Italica) during storage at isothermal and non-isothermal conditions," International Journal of Refrigeration, vol. 34, no. 8, pp. 2136-2144, 2011.

[17] A. Podsędek, "Natural antioxidants and antioxidant capacity of Brassica vegetables: a review," LWT-Food Science and Technology, vol. 40, no. 1, pp. 1-11, 2007.

[18] A. Vega-Gálvez, K. Di Scala, K. Rodríguez et al., "Effect of airdrying temperature on physico-chemical properties, antioxidant capacity, colour and total phenolic content of red pepper (Capsicum annuum, L. var. Hungarian)," Food Chemistry, vol. 117, no. 4, pp. 647-653, 2009.

[19] P. S. Negi and S. K. Roy, "Effect of drying conditions on quality of green leaves during long term storage," Food Research International, vol. 34, no. 4, pp. 283-287, 2001.

[20] K. Di Scala, A. Vega-Gálvez, E. Uribe et al., "Changes of quality characteristics of pepino fruit (Solanum muricatum Ait) during convective drying," International Journal of Food Science and Technology, vol. 46, no. 4, pp. 746-753, 2011.

[21] C. I. Nindo, T. Sun, S. W. Wang, J. Tang, and J. R. Powers, "Evaluation of drying technologies for retention of physical quality and antioxidants in asparagus (Asparagus officinalis, L.)," LWTFood Science and Technology, vol. 36, no. 5, pp. 507-516, 2003.

[22] Z.-W. Cui, S.-Y. Xu, and D.-W. Sun, "Effect of microwavevacuum drying on the carotenoids retention of carrot slices and chlorophyll retention of Chinese chive leaves," Drying Technology, vol. 22, no. 3, pp. 563-575, 2004.

[23] R. Deliza, A. Rosenthal, F. B. D. Abadio, C. H. O. Silva, and C. Castillo, "Application of high pressure technology in the fruit juice processing: benefits perceived by consumers," Journal of Food Engineering, vol. 67, no. 1-2, pp. 241-246, 2005.

[24] M. C. Nicoli, M. Anese, L. Manzocco, and C. R. Lerici, "Antioxidant properties of coffee brews in relation to the roasting degree," LWT-Food Science and Technology, vol. 30, no. 3, pp. 292-297, 1997. 

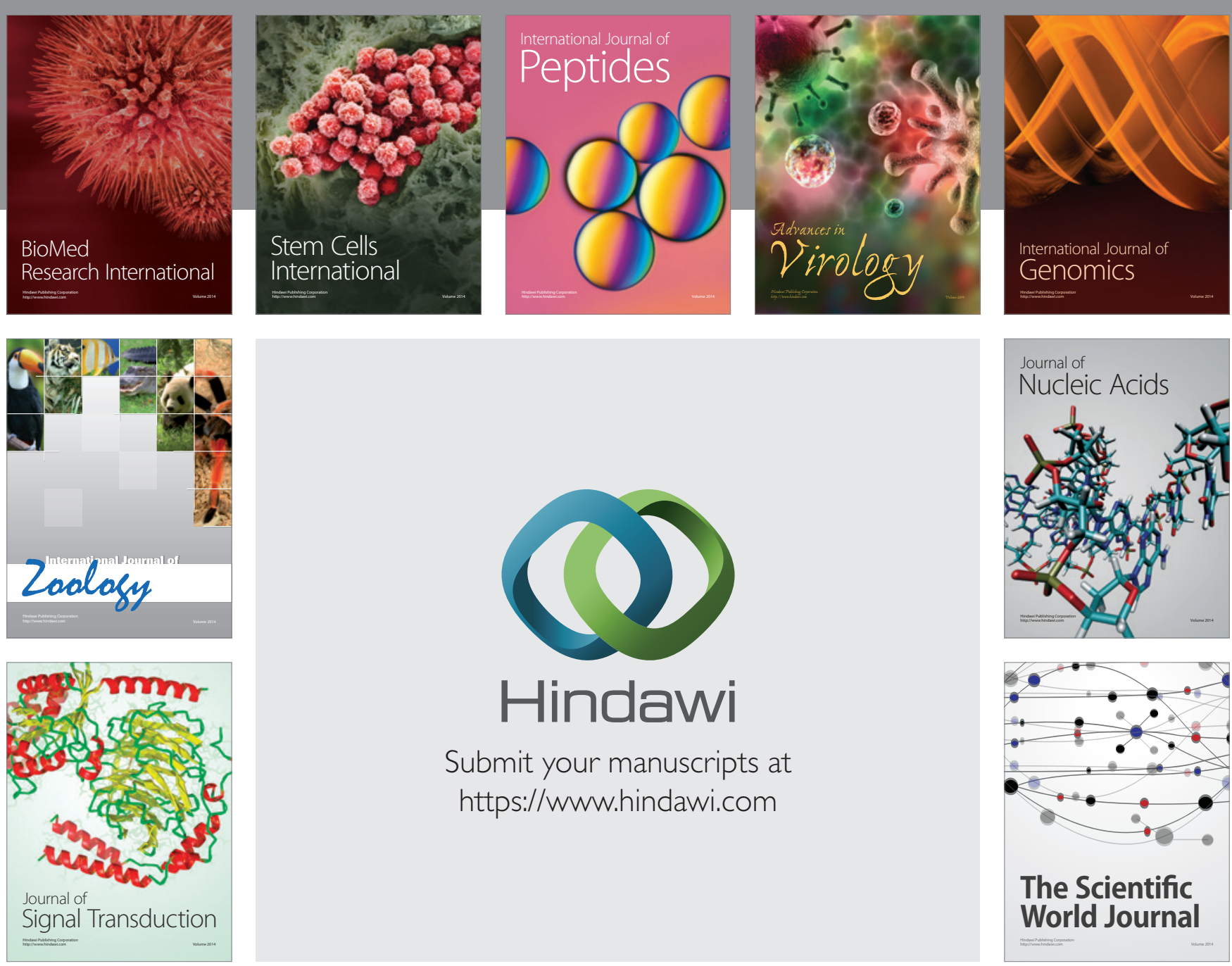

Submit your manuscripts at

https://www.hindawi.com
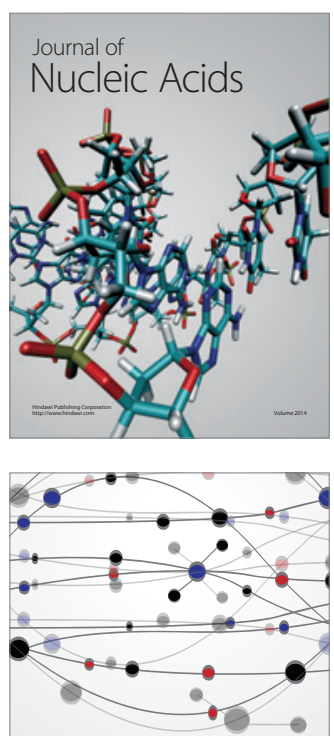

The Scientific World Journal
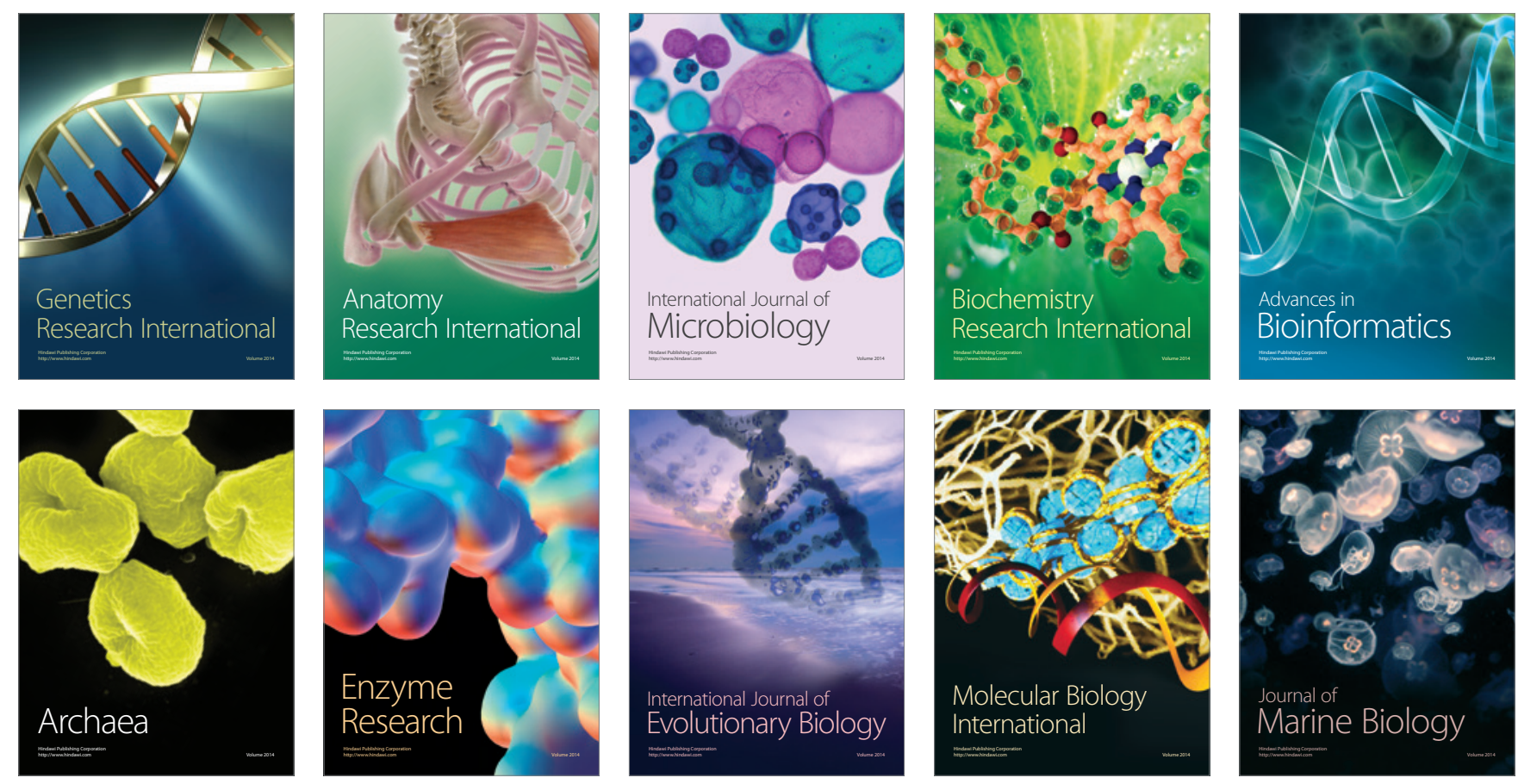